Article

\title{
Long-Term Course of Hypothyroidism Detected through Neonatal TSH Screening in a Population-Based Cohort of Very Preterm Infants Born at Less Than 32 Weeks of Gestation
}

\author{
Birgit Odenwald ${ }^{1, *}+\mathbb{D}$, Aline Fischer ${ }^{2, \dagger}$, Wulf Röschinger ${ }^{3}$, Bernhard Liebl ${ }^{1}$, Heinrich Schmidt ${ }^{4, \ddagger}$ \\ and Uta Nennstiel $1, *, \ddagger$
}

\section{check for} updates

Citation: Odenwald, B.; Fischer, A.; Röschinger, W.; Liebl, B.; Schmidt, H.; Nennstiel, U. Long-Term Course of Hypothyroidism Detected through Neonatal TSH Screening in a

Population-Based Cohort of Very Preterm Infants Born at Less Than 32 Weeks of Gestation. Int. J. Neonatal Screen. 2021, 7, 65. https://doi.org/ 10.3390/ijns7040065

Academic Editor: Ralph Fingerhut

Received: 2 September 2021

Accepted: 6 October 2021

Published: 13 October 2021

Publisher's Note: MDPI stays neutral with regard to jurisdictional claims in published maps and institutional affiliations.

Copyright: (c) 2021 by the authors. Licensee MDPI, Basel, Switzerland. This article is an open access article distributed under the terms and conditions of the Creative Commons Attribution (CC BY) license (https:/ / creativecommons.org/licenses/by/ $4.0 /)$.
1 Newborn Screening Centre/State Institute of Health, Bavarian Health and Food Safety Authority, 85764 Oberschleissheim, Germany; Bernhard.Liebl@lgl.bayern.de

2 Paediatric and Youth Medicine Clinic, Klinikum Dritter Orden, 80638 Munich, Germany; aline.fischer@dritter-orden.de

3 Newborn Screening Unit, Becker and Colleagues Laboratory, 81737 Munich, Germany; W.Roeschinger@labor-becker.de

4 Paediatric Endocrinology, Dr. von Hauner Children's Hospital, Ludwig-Maximilians-University, 80337 Munich, Germany; Heinrich.Schmidt@med.uni-muenchen.de

* Correspondence: birgit.odenwald@lgl.bayern.de (B.O.); uta.nennstiel@lgl.bayern.de (U.N.)

+ These authors contributed equally to this work.

$\ddagger$ Joint last authors.

Abstract: After several decades of successful newborn screening (NBS) for congenital hypothyroidism, the optimal hypothyroidism NBS algorithm for very preterm infants is still controversial. Due to concerns about an elevated risk of a false-negative initial thyroid-stimulation hormone (TSH) screening, repeat NBS has been implemented for this group. While transient hypothyroidism is known to be more frequent among very preterm infants, the prevalence of permanent hypothyroidism is generally assumed to be the same as in more mature newborns. This study analyses screening and long-term follow-up data from the population-based cohort of 51 infants born from 1999-2017 at less than 32 weeks of gestation and diagnosed with hypothyroidism after NBS in the German Federal State of Bavaria (total number of infants screened 2,107,864). Severe permanent hypothyroidism was always detected at initial TSH screening unless there was a known confounding factor. Cases detected by repeat screening after a negative initial screen most frequently proved to be transient, less frequently mild permanent, or a definitive diagnosis was not possible because of inadequate re-evaluation of the thyroid axis. The prevalence of both permanent and transient hypothyroidism was elevated compared to a cohort of children from the same region born at a higher gestational age. The results seem to support the need for the repeated NBS of very preterm infants. However, as the recommendation to treat mild hypothyroidism is not based on high quality evidence, important issues for future research include treatment outcome studies or even a general review of whether this diagnosis meets the screening criteria. Meanwhile, involving a paediatric endocrinologist in treatment decisions is crucial for optimising the benefit of hypothyroidism screening for this particularly vulnerable group.

Keywords: neonatal screening; thyroid-stimulation hormone; congenital hypothyroidism; preterm infant; follow-up; re-evaluation

\section{Introduction}

The newborn screening (NBS) of primary congenital hypothyroidism is widely acknowledged as a major achievement and has been established in many programmes worldwide since its development in the 1970s. Left untreated or treated late, hypothyroidism is a cause of irreversible neurodevelopmental damage, growth retardation, and 
metabolic complications. Early detection and treatment of hypothyroidism by NBS has been proven to prevent adverse outcomes successfully [1,2].

The detection rate of primary congenital hypothyroidism in NBS programmes lies between 3 and 5 per 10,000 births. The most common screening strategy is the detection of elevated levels of pituitary thyroid-stimulating hormone (TSH) in dried blood spots during the first week of life. After a positive screening result, the European expert societies advise confirmatory serum testing of the thyroid hormone free thyroxine (FT4) and TSH, and, if hypothyroidism is confirmed, an immediate start of oral Levothyroxine (LT4) treatment, ideally within two weeks of birth [1]. In addition to severe hypothyroidism with FT4 concentrations clearly below the age-specific reference intervals, this treatment recommendation explicitly includes "mild hypothyroidism", for neonates defined as an elevation of serum TSH above $20 \mathrm{mU} / \mathrm{L}$ with normal FT4 values [1].

While being a relatively straightforward matter for mature infants, the hypothyroidism screening process is posing some widely debated additional difficulties for very preterm infants $[1,3,4]$. The thyroid function patterns of very preterm infants have been shown to differ considerably from those of mature infants [5]. The terms "transient hypothyroxinaemia of prematurity" (THOP) and "delayed TSH elevation" summarise two main characteristics of the preterm thyroid situation that may interfere with NBS. Incomplete maturation of the hypothalamic-pituitary-thyroid (HPT) axis, the effects of neonatal medication, iodine deficiency or iodine excess, or serious neonatal non-thyroidal illness (NTI) have been described as possible causative factors of these phenomena [6-9]. Several follow-up studies have shown that thyroid function imbalance with delayed TSH rise among preterm infants often but not always proves transient $[10,11]$. The necessity to treat THOP, moderate TSH elevation with normal FT4, or mild transient hypothyroidism is a complex and controversial subject lacking clear evidence $[1,4,12,13]$. The prophylactic LT4 treatment of all preterms has not been shown to be beneficial [14] and several authors have emphasised the risks of overtreatment $[10,15,16]$. However, because of the neurodevelopmental dangers of hypothyroidism, there is a broad consensus among the majority of authors to treat all forms of hypothyroidism early and to re-evaluate thyroid function later, if appropriate-usually after the age of 2 or 3 years, when the highly thyroid-sensitive period of neurodevelopment has passed [1,3,17], under certain conditions from 6 months of age [1]. According to current recommendations for thyroid re-evaluation with discontinuation of LT4 therapy, slight TSH elevations below $10 \mathrm{mU} / \mathrm{L}$ are to be retested without immediately resuming therapy, while an off-therapy TSH rise $\geq 10 \mathrm{mU} / \mathrm{L}$ confirms primary hypothyroidism [1].

In order to avoid false-negative screening results, repeat NBS for preterm and low birth weight infants is broadly recommended and has been implemented into many NBS programmes [1,18]. However, there is no consensus about the necessity, optimal timing, and frequency of repeat NBS samples, and algorithms vary widely [19]. German NBS regulations stipulate a first screening of all neonates between 36 and $72 \mathrm{~h}$ of birth and a secondary screening of infants born at less than 32 weeks of gestation when they reach the equivalent of 32 weeks gestational age [20]. Several institutions perform supplementary thyroid function tests for preterm infants regularly.

An analysis of population-based German NBS data over a 5-year period indicated a 4-fold increased prevalence of hypothyroidism among infants born at less than 32 weeks of gestation, $73 \%$ of these with a delayed TSH rise [21]. Almost half of these cases were not detected by the official NBS algorithm but by supplementary repeat screening samples. Based on the screening results of 10,000,000 newborns in Germany from 2006-2019, the prevalence of congenital hypothyroidism was 3.1/10,000 overall, and 17.75/10,000 for very preterm infants born before 32 weeks of gestation [22]. As the nationwide NBS data do not include detailed background information and further follow-up data, it was unknown whether the observed high prevalence of hypothyroidism was due to an elevated frequency of transient or permanent forms, or both. For other countries, high proportions of transient hypothyroidism among preterm infants have been shown [11,23-28], but assessments of the prevalence of permanent hypothyroidism in this group are scarce and contradictory [26]. 
Most authors have presumed that the frequency of permanent hypothyroidism is equal among preterm and mature infants $[10,29,30]$.

In the German Federal State of Bavaria, an ongoing regional population-based followup study was initiated in 1999 to evaluate neonatal screening. The present study used this database for an evaluation of the determinants and frequency of permanent and transient hypothyroidism among very preterm infants born at less than 32 weeks of gestation. In addition, prevalences were compared between this very preterm group and children born at higher gestational ages. Thus, this paper aims to contribute to the evidence base for the hypothyroidism screening of preterm infants.

\section{Materials and Methods}

This analysis was part of the population-based long-term follow-up study of children diagnosed with a target disease of NBS in the German Federal State of Bavaria. This study was approved by the ethics commission of the Bavarian State Chamber of Physicians (registration code 04016, approval date 23 March 2004). The detailed analysis included all children with a gestational age below 32 weeks who were born and screened in Bavaria from 1999 to 2017 and diagnosed with hypothyroidism in need of treatment during the neonatal screening process, excepting children with identified genetic syndromes or severe malformations. The analysis was aimed to distinguish between permanent and transient hypothyroidism for each child included.

Screening was performed in accordance with German guidelines for the prevention of disease in children [20]: Blood is sampled at 36 to $72 \mathrm{~h}$ after birth, and retesting is advised for samples taken under the influence of corticosteroid or catecholamine administration, or blood transfusion, or in infants born $<32$ weeks of gestation. Repeat NBS at the equivalent of 32 weeks gestational age has been advocated by paediatric societies for the entire observational period of this study and was incorporated into the official regulations in 2005. TSH was measured from dried blood filter cards by immunological assays (AutoDELFIA ${ }^{\circledR}$ ) in the two specialised laboratories licensed for neonatal screening in Bavaria. TSH screening cut-off values were $<20 \mathrm{mU} / \mathrm{L}$ for the first days of life, $<15 \mathrm{mU} / \mathrm{L}$ for days $2-5$ (laboratory 1 ) or 4-5 (laboratory 2), and $<10 \mathrm{mU} / \mathrm{L}$ from day 6.

Tracking of abnormal values and the long-term follow-up study were carried out at the Bavarian screening centre, which for both screening laboratories is located at the Bavarian Health and Food Safety Authority. Follow-up information was obtained via medical reports and parental questionnaires or, in some cases, telephone inquiries with families or paediatricians. Parents' informed consent was obtained separately for screening, tracking, follow-up by questionnaires, and follow-up by medical records. With some differences in methodology and a shorter follow-up period, data on part of the present cohort have already been reported in a German-language dissertation [31].

Diagnostic criteria were assessed in accordance with the European Consensus Guidelines on Screening, Diagnosis, and Management of Congenital Hypothyroidism published by the European Society for Paediatric Endocrinology (ESPE) in 2014 [3] and updated in 2020 [1].

Diagnostic criteria for the inclusion into the analysis were the biochemical conditions which, according to these guidelines, clearly indicate the decision to initiate LT4 treatment in case of neonatal screening TSH elevations: Serum TSH $\geq 20 \mathrm{mU} / \mathrm{L}$, or TSH elevated, but lower than $20 \mathrm{mU} / \mathrm{L}$ and FT4 below cut-off. Serum FT4 lower cut-off was set $10 \mathrm{pmol} / \mathrm{L}$ if there was no laboratory-specific FT4 normative value range given. Serum FT4 was rated very low if $<5 \mathrm{pmol} / \mathrm{L}$ and low if $5-<10 \mathrm{pmol} / \mathrm{L}$.

The final diagnosis of permanent hypothyroidism required at least one of the following conditions:

1. Conclusive confirmation of thyroid dysgenesis, thyroid ectopy, or athyreosis, on imaging.

2. Confirmation of severe dyshormonogenesis by molecular genetic testing. 
3. Positive result of off-treatment re-evaluation of the thyroid axis, or positive result of LT4 dose decreasing trial ( $=$ increase in TSH concentration to $\geq 10 \mathrm{mU} / \mathrm{L}$ after 4 weeks off-treatment or after 2 to 3 weeks of LT4 dose decreased by $30 \%$ ).

4. Rise of venous TSH concentration under ongoing LT4 treatment after the first year of life, in combination with repeated increases of LT4 dosage, age and weight appropriate, over years with regular controls of thyroid function.

In addition, the final diagnosis "permanent" was further differentiated:

- Severe permanent hypothyroidism when there was evidence of a significant morphologic abnormality of the thyroid gland or evidence of a decreased FT4 on re-evaluation of thyroid function.

- Mild permanent hypothyroidism when there was no evidence of a morphologic abnormality of the thyroid gland and a TSH increase to above $10 \mathrm{mU} / \mathrm{L}$ with FT4 in the normal range was detected on re-evaluation.

The final diagnosis of transient hypothyroidism or TSH elevation required a steady euthyroid state (TSH and FT4 normal) after discontinuation of LT4 therapy.

The final diagnosis was classified inconclusive if none of the "permanent" criteria was fulfilled but LT4 therapy was continued, and re-evaluation of the thyroid axis was inadequate or not carried out until the 4 th year of life or later. The classification unknown was used if sufficient information for a final diagnosis was not available because of loss to follow-up.

For prevalence comparison with children born at a higher gestational age, the same inclusion and diagnostic criteria were applied to the corresponding subgroup of the Bavarian population-based long-term study. Follow-up of all children covered the birth years from 1999 to 2013. To increase the number of very preterm cases, follow-up was extended up to the birth year of 2017 for infants born $<32$ weeks. Therefore, the calculations of prevalence refer to birth years 1999-2013 for births $\geq 32$ weeks of gestation, and to 1999-2017 for births $<32$ weeks. With a screening rate of $98.6 \%$, the screening database included all children born, screened, and registered in Bavaria. Reference total birth numbers were 1,615,592 births $\geq 32$ weeks of gestation (1999-2013) and 23,171 births <32 weeks of gestation (1999-2017). Prevalences were calculated per 10,000 births of each gestational age group.

Screening and tracking data were documented in Access ${ }^{\circledR}$ (1999-2012) and Oracle (since 2013) databases at the screening centre. All relevant data were entered retrospectively into a separate pseudonymised Access ${ }^{\circledR}$ database and analysed with IBM $^{\circledR}$ SPSS $^{\circledR}$ Statistics for Windows, Version 25.0. (IBM Corp., Armonk, NY, USA) software, using non-parametric tests at a level of significance of $p<0.05$, where appropriate.

\section{Results}

Among all the infants born, screened, and registered in Bavaria from 1999 to 2017 $(N=2,107,864$; screening rate $98.6 \%)$, a total of 51 infants born preterm at a gestational age of less than 32 weeks had a diagnosis of hypothyroidism treated with LT4 after neonatal screening and were included in this analysis. Prevalence of treated hypothyroidism thus was 22:10,000 in this subgroup of preterms (number of births $<32$ weeks of gestation $N=23,171$ ).

For five children follow-up information was unavailable. One of these children died at the age of 7 months, two families declined follow-up, and two families were lost to followup. Of the 46 children with follow-up information, for 37 children a definite diagnosis of permanent or transient hypothyroidism could be established, while for 9 children evidence was inconclusive (Figure 1).

Table 1 shows the main characteristics of the study population, Table 2 shows the individual characteristics grouped by final diagnoses. 


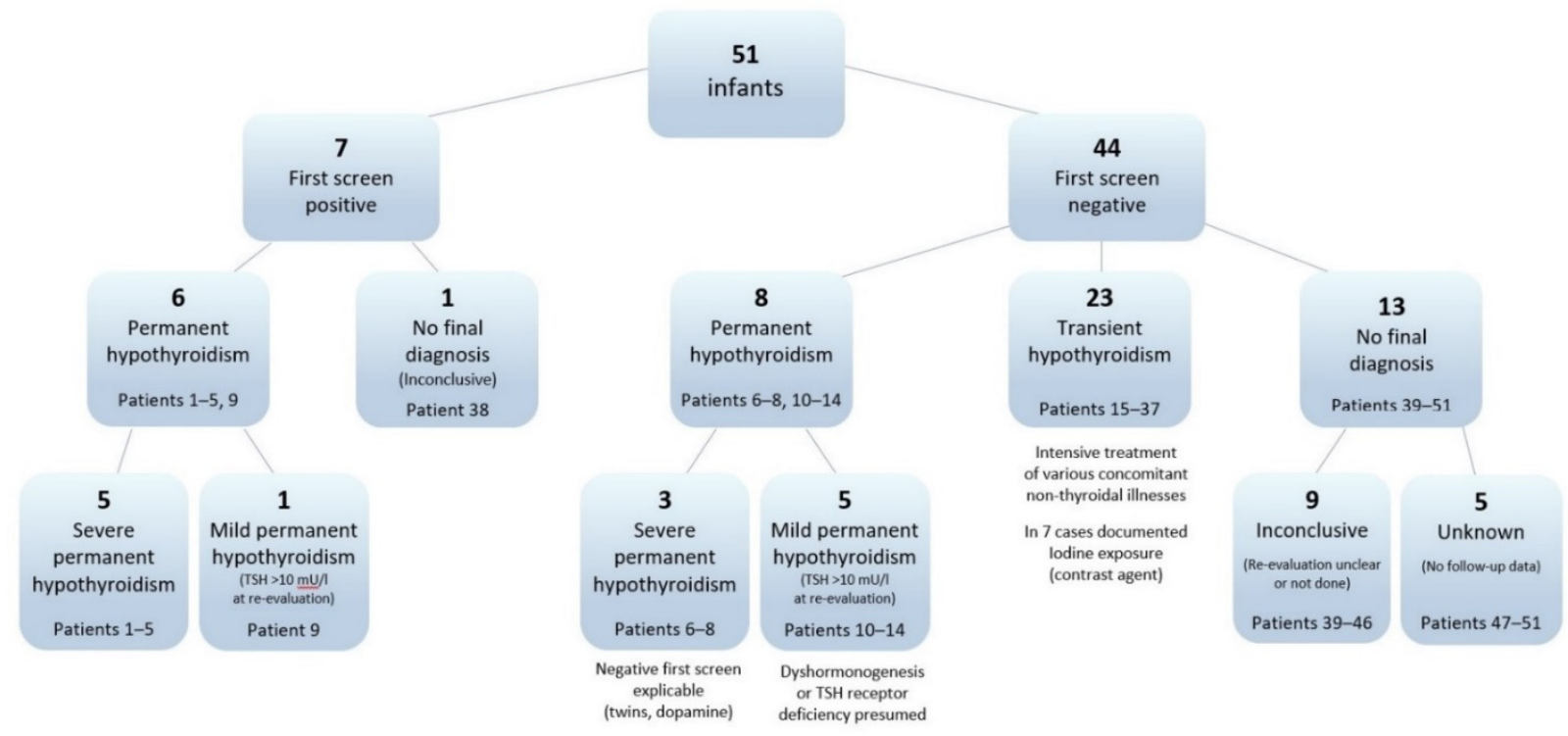

Figure 1. Overview of first screen results and final diagnoses.

Table 1. Main population characteristics and results.

\begin{tabular}{|c|c|c|c|}
\hline \multicolumn{2}{|l|}{ Category } & $n$ & $\%$ \\
\hline \multirow{3}{*}{ Gestational age (weeks) } & $23-25$ & 16 & 31.4 \\
\hline & $26-28$ & 12 & 23.5 \\
\hline & $29-31$ & 23 & 45.1 \\
\hline \multirow{4}{*}{ Birth weight (BW) category } & LBW (<2500 g) & 6 & 11.8 \\
\hline & VLBW (<1500 g) & 15 & 29.4 \\
\hline & ELBW (<1000 g) & 30 & 58.8 \\
\hline & SGA & 6 & 11.8 \\
\hline \multirow{2}{*}{ Sex } & Male & 30 & 58.8 \\
\hline & Female & 21 & 41.2 \\
\hline \multirow{3}{*}{ Age at initial screening } & $<36 \mathrm{~h}$ & 5 & 9.8 \\
\hline & $36-72 \mathrm{~h}$ & 41 & 80.4 \\
\hline & $>72 \mathrm{~h}$ & 5 & 9.8 \\
\hline \multirow{5}{*}{$\begin{array}{l}\text { Serum thyroid-stimulation hormone (TSH) } \\
\text { category } \\
\text { before start of therapy }\end{array}$} & $>100 \mathrm{mU} / \mathrm{L}$ & 20 & 39.2 \\
\hline & $>50-100 \mathrm{mU} / \mathrm{L}$ & 12 & 23.5 \\
\hline & $>20-50 \mathrm{mU} / \mathrm{L}$ & 16 & 31.4 \\
\hline & $<20 \mathrm{mU} / \mathrm{L}$ & 1 & 2.0 \\
\hline & N/A & 2 & 3.9 \\
\hline \multirow{5}{*}{$\begin{array}{l}\text { Serum free thyroxine (FT4) category } \\
\text { before start of therapy }\end{array}$} & $<5 \mathrm{pmol} / \mathrm{L}$ & 9 & 17.6 \\
\hline & $5-<10 \mathrm{pmol} / \mathrm{L}$ & 19 & 37.3 \\
\hline & $10-<15 \mathrm{pmol} / \mathrm{L}$ & 14 & 27.5 \\
\hline & $\geq 15 \mathrm{pmol} / \mathrm{L}$ & 2 & 3.9 \\
\hline & $\mathrm{N} / \mathrm{A}$ & 7 & 13.7 \\
\hline \multirow{2}{*}{ Follow-up thyroid care } & Paediatric endocrinology & 15 & 29.4 \\
\hline & General paediatrician & 36 & 70.6 \\
\hline \multirow{6}{*}{ Final diagnostic category } & Permanent hypothyroidism & 14 & 27.5 \\
\hline & severe & 8 & 15.7 \\
\hline & mild & 6 & 11.8 \\
\hline & Transient hypothyroidism & 23 & 45.1 \\
\hline & Inconclusive & 9 & 17.6 \\
\hline & Unknown & 5 & 9.8 \\
\hline
\end{tabular}


Table 2. Individual patient characteristics.

\begin{tabular}{|c|c|c|c|c|c|c|c|c|c|c|c|}
\hline \multirow{2}{*}{$\begin{array}{c}\text { Final } \\
\text { Diagnosis After } \\
\text { Long-Term Follow-Up }\end{array}$} & \multirow{2}{*}{$\begin{array}{c}\text { Patient } \\
\text { Number }\end{array}$} & \multirow[t]{2}{*}{ Sex } & \multirow{2}{*}{ Birth Weight (g) } & \multicolumn{2}{|c|}{$\begin{array}{c}\text { Gestational Age/Postmenstrual } \\
\text { Age (Weeks) }\end{array}$} & \multicolumn{2}{|c|}{ Newborn Screening Results } & \multicolumn{2}{|c|}{$\begin{array}{l}\text { Confirmatory Testing } \\
\text { Results (Serum) }\end{array}$} & \multirow{2}{*}{$\begin{array}{l}\text { L-T4 Dosage at Age } \\
2 \text { Years }(\mu \mathrm{g} / \mathrm{kg})\end{array}$} & \multirow{2}{*}{ Annotations } \\
\hline & & & & At Birth & At Diagnosis & First Screen & Max. TSH (mU/L) & TSH (mU/L) & FT4 (pmol/L) & & \\
\hline \multirow{7}{*}{$\begin{array}{l}\text { Severe permanent } \\
\text { hypothyroidism }\end{array}$} & 1 & $\mathrm{f}$ & 1600 & 29 & 30 & pos. & 323 & $>100$ & 1.4 & 3.8 & $\begin{array}{l}\text { Thyroid dysplasia. Dizygotic } \\
\text { twin of euthyroid co-twin. }\end{array}$ \\
\hline & 2 & $\mathrm{~m}$ & 1550 & 30 & 32 & pos. & 532 & 1365 & 1.7 & 5.8 & Athyreosis. \\
\hline & 3 & $\mathrm{~m}$ & 960 & 27 & 28 & pos. & 222 & 101 & N/A & 4.6 & Thyroid dysplasia. \\
\hline & 4 & $\mathrm{f}$ & 1450 & 30 & 32 & pos. & 218 & 459 & N/A & 3.1 & $\begin{array}{l}\text { Thyroid dysplasia. Identical } \\
\text { twin of euthyroid co-twin. }\end{array}$ \\
\hline & 6 & $\mathrm{f}$ & 1200 & 28 & 34 & neg. & 731 & $>100$ & $<0.3$ & 4.4 & $\begin{array}{l}\text { Athyreosis. Identical twin of } \\
\text { euthyroid co-twin. Delayed } \\
\text { re-screening in spite of tracking }\end{array}$ \\
\hline & 7 & $\mathrm{f}$ & 1115 & 29 & 39 & neg. & 875 & $>100$ & 1.5 & 5 & $\begin{array}{l}\text { Thyroid dysplasia. Identical } \\
\text { twin of euthyroid co-twin. Born } \\
\text { before implementation of } \\
\text { re-screening at } 32 \text { weeks. }\end{array}$ \\
\hline & 8 & $\mathrm{~m}$ & 460 & 25 & 28 & neg. & 149 & 280 & TT4 low & 3 & $\begin{array}{l}\text { First screen under the influence } \\
\text { of high-dose dopamine. }\end{array}$ \\
\hline \multirow{5}{*}{$\begin{array}{l}\text { Mild permanent } \\
\text { hypothyroidism }\end{array}$} & 9 & $\mathrm{f}$ & 1300 & 29 & 29 & pos. & 122 & 92 & 12.9 & 4 & $\begin{array}{l}\text { Family history of } \\
\text { hypothyroidism. }\end{array}$ \\
\hline & 11 & $\mathrm{~m}$ & 1730 & 30 & 40 & neg. & 275 & $>100$ & 6.7 & 2.8 & Negative control at age 2 weeks \\
\hline & 12 & $\mathrm{f}$ & 1200 & 29 & 33 & neg. & 34 & 62 & 7.0 & 4.3 & $\begin{array}{l}\text { Identical twin of patient } 13 . \\
\text { Family history of } \\
\text { hypothyroidism. }\end{array}$ \\
\hline & 13 & $\mathrm{f}$ & 1420 & 29 & 33 & neg. & 11 & 30 & 11.1 & 3.7 & $\begin{array}{l}\text { Identical twin of patient } 12 . \\
\text { Family history of } \\
\text { hypothyroidism. }\end{array}$ \\
\hline & 14 & $\mathrm{~m}$ & 1495 & 30 & 34 & neg. & 23 & 27 & 12.9 & 3.3 & $\begin{array}{l}\text { Family history of thyroid } \\
\text { disorders }\end{array}$ \\
\hline
\end{tabular}


Table 2. Cont.

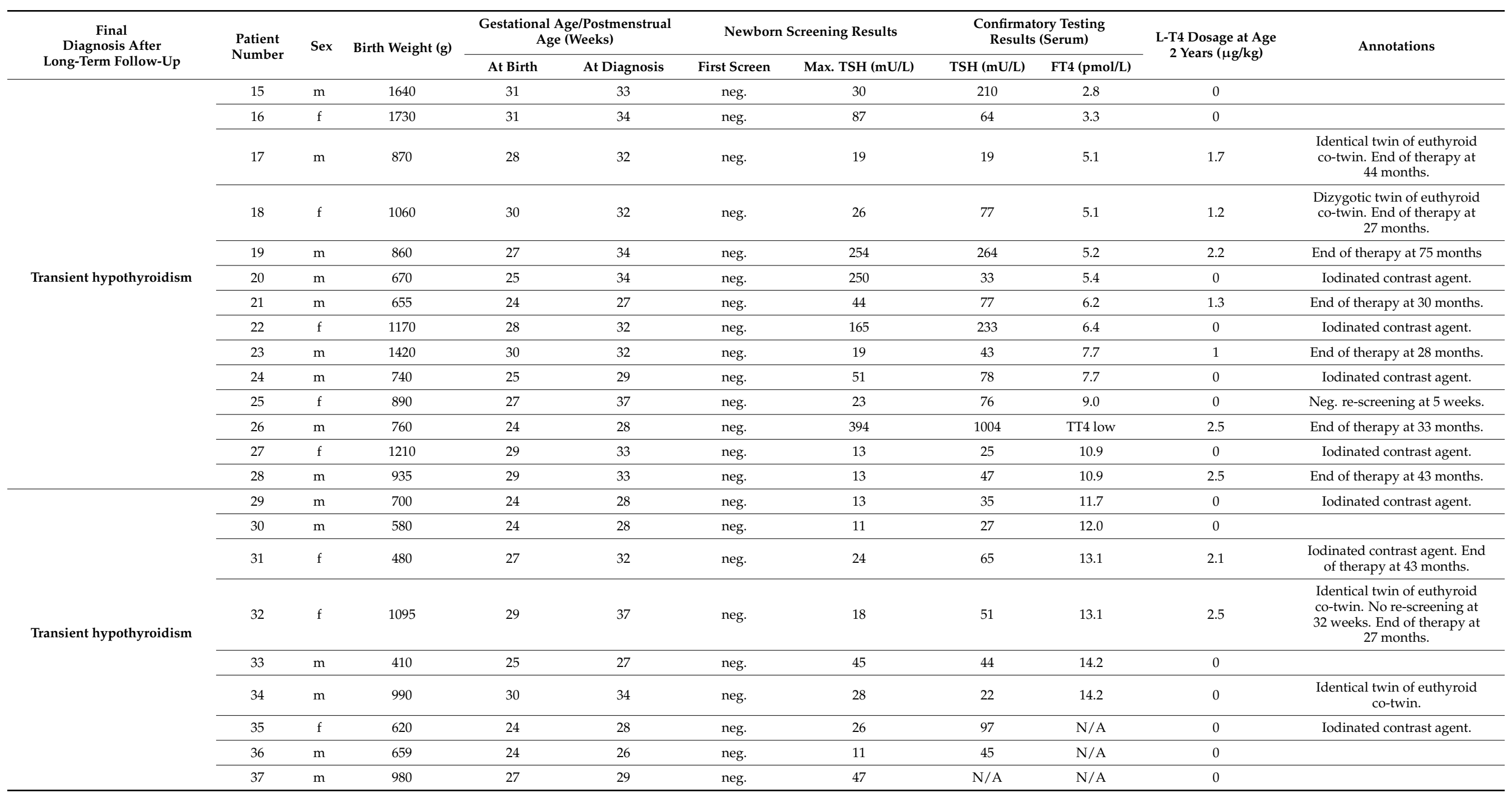


Table 2. Cont.

\begin{tabular}{|c|c|c|c|c|c|c|c|c|c|c|c|}
\hline \multirow{2}{*}{$\begin{array}{c}\text { Final } \\
\text { Diagnosis After } \\
\text { Long-Term Follow-Up }\end{array}$} & \multirow{2}{*}{$\begin{array}{l}\text { Patient } \\
\text { Number }\end{array}$} & \multirow{2}{*}{ Sex } & \multirow{2}{*}{ Birth Weight (g) } & \multicolumn{2}{|c|}{$\begin{array}{l}\text { Gestational Age/Postmenstrual } \\
\text { Age (Weeks) }\end{array}$} & \multicolumn{2}{|c|}{ Newborn Screening Results } & \multicolumn{2}{|c|}{$\begin{array}{c}\text { Confirmatory Testing } \\
\text { Results (Serum) }\end{array}$} & \multirow{2}{*}{$\begin{array}{l}\text { L-T4 Dosage at Age } \\
2 \text { Years ( } \mu \mathrm{g} / \mathrm{kg})\end{array}$} & \multirow{2}{*}{ Annotations } \\
\hline & & & & At Birth & At Diagnosis & First Screen & Max. TSH (mU/L) & TSH (mU/L) & FT4 (pmol/L) & & \\
\hline \multirow{8}{*}{ Inconclusive } & 38 & $\mathrm{~m}$ & 1780 & 31 & 32 & pos. & 71 & $\mathrm{~N} / \mathrm{A}$ & 11.7 & 3.4 & $\begin{array}{c}\text { Mostly extremely low TSH } \\
\text { values under treatment, } \\
\text { maternal autoimmune } \\
\text { thyroiditis mentioned in } \\
\text { medical report. }\end{array}$ \\
\hline & 39 & $\mathrm{~m}$ & 570 & 24 & 27 & neg. & 52 & 336 & 5.1 & 0.9 & Iodinated contrast agent. \\
\hline & 40 & $\mathrm{~m}$ & 740 & 27 & 32 & neg. & 52 & $>100$ & 5.1 & 1.8 & \\
\hline & 42 & $\mathrm{~m}$ & 540 & 24 & 47 & neg. & 52 & $>100$ & 9.0 & 2.1 & $\begin{array}{l}\text { Late treatment due to } \\
\text { fluctuations or thyroid function } \\
\text { tests and presumed transience. }\end{array}$ \\
\hline & 43 & $\mathrm{f}$ & 806 & 27 & 33 & neg. & 20 & 57 & 9.5 & 1.2 & $\begin{array}{l}\text { Identical twin of euthyroid } \\
\text { co-twin. Family history of } \\
\text { hypothyroidism. }\end{array}$ \\
\hline & 44 & $\mathrm{f}$ & 620 & 26 & 35 & neg. & 18 & 29 & 11.7 & 2.5 & Iodinated contrast agent. \\
\hline & 45 & $\mathrm{~m}$ & 850 & 31 & 33 & neg. & 32 & 81 & 14.5 & 2.7 & Iodinated contrast agent. \\
\hline & 46 & $\mathrm{f}$ & 1138 & 31 & 40 & neg. & 24 & 24 & 19.4 & 2.0 & $\begin{array}{l}\text { Identical twin of euthyroid } \\
\text { co-twin. Re-screening neg. at } \\
2 \text { weeks, pos. at } 8 \text { weeks. }\end{array}$ \\
\hline \multirow{5}{*}{ Unknown } & 47 & $\mathrm{~m}$ & 740 & 25 & 29 & neg. & 162 & 323 & 2.8 & N/A & \\
\hline & 48 & $\mathrm{f}$ & 560 & 23 & 33 & neg. & 137 & 157 & 5.1 & $\mathrm{~N} / \mathrm{A}$ & Iodinated contrast agent. \\
\hline & 49 & $\mathrm{f}$ & 720 & 25 & 33 & neg. & 60 & 128 & 7.7 & $\mathrm{~N} / \mathrm{A}$ & Iodinated contrast agent. \\
\hline & 50 & $\mathrm{~m}$ & 841 & 29 & 35 & neg. & 27 & 29 & 7.8 & $\mathrm{~N} / \mathrm{A}$ & \\
\hline & 51 & $\mathrm{~m}$ & 805 & 27 & 35 & neg. & 15 & 22 & 15.4 & N/A & \\
\hline
\end{tabular}




\subsection{Permanent Hypothyroidism}

Permanent hypothyroidism was confirmed for 14 children (27.5\%), namely, 6 children with a positive result of initial screening (Table 2, patients 1-5 and 9) and an additional 8 children with a negative result of initial screening, detected after a positive screening control (patients 6-8 and 10-14). On further differentiation, eight cases were classified as severe permanent hypothyroidism (patients 1-8) and six cases as mild permanent hypothyroidism (patients 9-14). Among the eight children with confirmed severe hypothyroidism, five had a positive initial screening (patients 1-5) and three had an explicably negative initial screening, the causative factors being feto-fetal transfusion by an identical euthyroid twin (patients 6 and 7) or high-dose dopamine treatment (patient 8). In four initially negative cases with the final classification of mild hypothyroidism, there were indications to suspect a hereditary form of hypothyroidism (patients 10, 12-14).

\subsection{Transient Hypothyroidism}

Transient hypothyroidism was confirmed for 23 children (45.1\%), all of whom had a negative initial screening result and critical concomitant illnesses with various medications in the neonatal intensive care unit. Maternal thyrostatic treatment or positive maternal antibodies were not mentioned in any of these patients' medical reports. An exposure to an iodine contrast agent preceding the TSH rise was documented for seven of these infants. Decreased FT4 levels before initiation of therapy were found in 12 of these cases (patients 15-26). Treatment was terminated during the first year of life in eight cases $(34.8 \%)$, during the second year of life in five cases $(21.7 \%)$, in the third year of life in six cases $(26.1 \%)$, and at age three years or older in four cases $(17.3 \%)$.

\subsection{Comparison of Permanent and Transient Groups}

Maximum whole blood TSH values were significantly higher in the permanent than in the transient group (Figure 2). All infants with severe permanent hypothyroidism, 3 from 6 infants with mild permanent hypothyroidism and 4 from 23 infants with transient hypothyroidism had a whole blood TSH value above $100 \mathrm{mU} / \mathrm{L}$ at some point. Serum FT4 values before start of treatment were not available for seven infants (13.7\%). Median values and distribution of FT4 measurement before start of treatment showed a tendency towards lower values in the permanent group (Figure 3), with the lowest values found in the severe permanent group (Table 2). Hypothyroxinaemia (FT4 below $10 \mathrm{pmol} / \mathrm{L}$ or TT4 below cut-off) before the start of treatment was detected most frequently in the severe permanent group (severe permanent, $6 / 8,75 \%$; mild permanent, $3 / 6,50 \%$; transient, $12 / 23$, $52.3 \%$ ). The percentage of infants with severe hypothyroxinaemia before treatment (FT4 below $5 \mathrm{pmol} / \mathrm{L}$ ) was highest in the severe permanent group $(5 / 8 ; 62.5 \%)$ and lower in the mild permanent and transient group (mild permanent, $1 / 6,16.7 \%$; transient, $2 / 23,8.7 \%$ ).

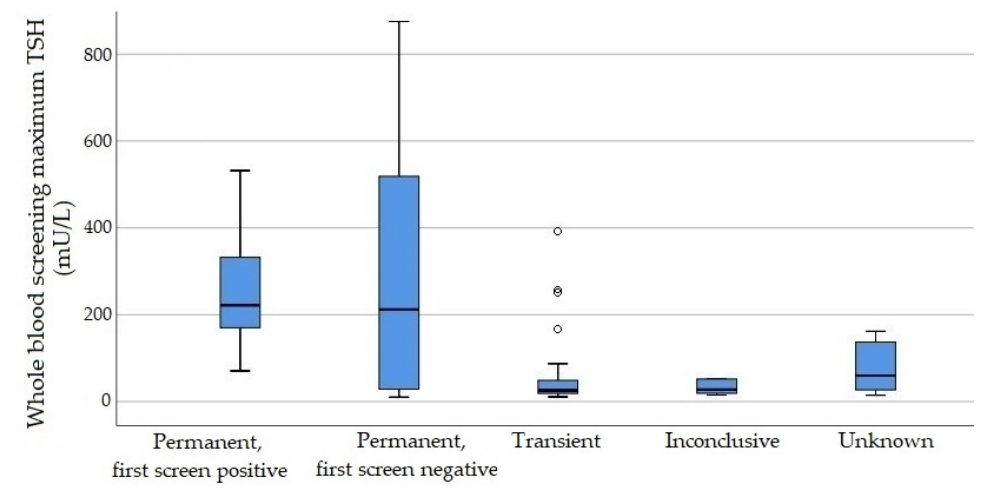

Figure 2. Maximum TSH screening values (whole blood, $\mathrm{mU} / \mathrm{L}$ ). Boxes represent median and interquartile range (IQR). Whiskers range between the minimum and maximum values, excluding outliers $>1.5$ IQR from the box which are represented by small circles. 


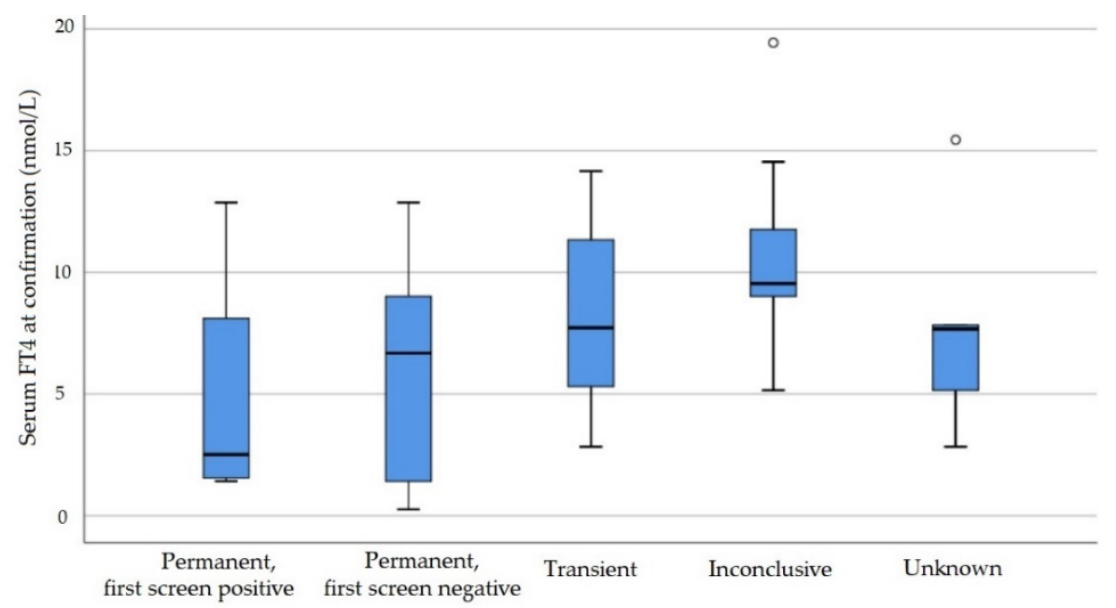

Figure 3. Free T4 values before initiation of treatment (serum, nmol/L). Boxes represent median and interquartile range (IQR). Whiskers range between the minimum and maximum values, excluding outliers $>1.5$ IQR from the box which are represented by small circles.

The gestational age and birth weight were significantly lower in the transient than in the permanent group, and infants with transient hypothyroidism were more often male. There was no observed difference in the frequency of infants small for gestational age (SGA) or Apgar scores between the groups (data not shown).

If still treated at age 2 years (permanent $n=14$, transient $n=10$ ), LT4 dosage was significantly higher in the permanent than in the transient group (Figure 4). While the highest daily dosage in the transient group was $2.5 \mu \mathrm{g} / \mathrm{kg}$, the lowest dosage in the permanent group was $2.8 \mu \mathrm{g} / \mathrm{kg}$ (Table 2).

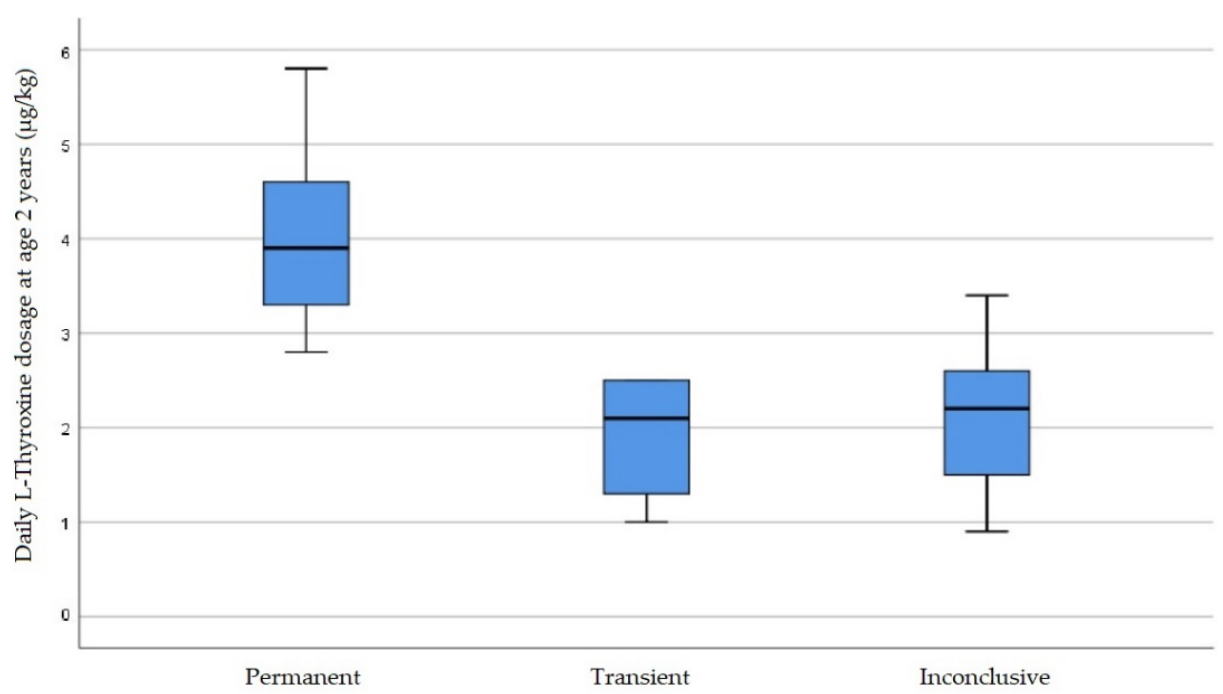

Figure 4. Daily dosage of Levothyroxine at the age of 2 years ( $\mu \mathrm{g}$ per $\mathrm{kg}$ body weight). Boxes represent median and interquartile range (IQR). Whiskers range between the minimum and maximum values.

\subsection{Inconclusive Cases}

Establishing a conclusive diagnosis was not possible for nine children although followup data were available. None of these children met criteria for permanent hypothyroidism, but treatment with a steady LT4 dosage was continued beyond the age of 3 years without definite re-evaluation. A paediatric endocrinologist was not involved in the decision to continue treatment in any of these cases. An exposure to iodine contrast agent preceding the TSH rise was documented for three of these children. A family history of thyroid 
disorders was known for two children. Dosage at age 2 years was mostly in the range of the transient group (Figure 3).

\subsection{Comparison of Prevalences between the Study Group and Infants Born $\geq 32$ Weeks} of Gestation

Overall prevalence of treated hypothyroidism or TSH elevation was nearly eight times higher among preterms born at $<32$ weeks of gestation $(22: 10,000)$ than among children born at higher gestational ages $(2.8: 10,000)$ (Table 3). Transient and unclear forms of hypothyroidism accounted for the most part of the observed difference. In relation to the comparison group, the relative frequency in the very preterm cohort was 2.5 for permanent hypothyroidism, and nearly 40 for transient hypothyroidism. A calculation restricted to severe hypothyroidism in the very preterm study group yielded a relative frequency of about 1.5, compared with permanent hypothyroidism overall at higher gestational ages.

Table 3. Comparison of prevalences $<32$ and $\geq 32$ weeks of gestation.

\begin{tabular}{|c|c|c|c|c|}
\hline & \multicolumn{2}{|c|}{$\begin{array}{c}\text { Study Group } \\
<32 \text { Weeks } \\
\text { of Gestation }^{1}\end{array}$} & \multicolumn{2}{|c|}{$\begin{array}{c}\text { Comparison Group } \\
\geq 32 \text { Weeks } \\
\text { of Gestation }^{2}\end{array}$} \\
\hline & $n$ & Per 10,000 births & $n$ & Per 10,000 births \\
\hline Permanent & 14 & 6.0 & 375 & 2.3 \\
\hline Transient & 23 & 9.9 & 40 & 0.25 \\
\hline Inconclusive & 9 & 3.9 & 7 & 0.04 \\
\hline Unknown & 5 & 2.2 & 22 & 0.14 \\
\hline Total & 51 & 22.0 & 444 & 2.8 \\
\hline
\end{tabular}

${ }^{1}$ This analysis: birth years 1999-2017; 23,171 births <32 weeks of gestation. ${ }^{2}$ Bavarian NBS follow-up study: birth years 1999-2013; 1,615,592 births $\geq 32$ weeks of gestation.

\section{Discussion}

This study set out to evaluate the determinants and the epidemiology of permanent and transient congenital hypothyroidism detected through NBS in very preterm infants born at less than 32 weeks of gestation, with a focus on the impact of repeat screening samples. Main results included the detectability of severe permanent hypothyroidism at initial TSH screening in the absence of a defined confounding factor, the detection of transient and mild permanent cases through TSH screening controls, and elevated prevalences of both permanent and transient hypothyroidism in the very preterm study group.

In reviewing the literature, no research was found on population-based prevalences of permanent and transient hypothyroidism stratified by gestational age. There is, however, a relatively small body of literature that is concerned with the follow-up of preterm or low birth weight infants with hypothyroidism detected in TSH newborn screening with one or more subsequent repetitions of TSH screening. These previous studies examined the frequency of hypothyroidism within their respective cohorts without differentiating between severe and mild permanent hypothyroidism. [23,25,26,28,32-34]. Detailed comparability between the studies was restricted because of the diversity of selected cohorts (e.g., (very) low birth weight, or preterms below 32, 33, or 37 weeks of gestation), differing screening algorithms (timing and cut-off values) and varying case definitions. In all but one of the studies [32], hypothyroidism was classified as permanent if re-evaluation off therapy caused a TSH rise (mostly using the cut-off of $10 \mathrm{mU} / \mathrm{L}$ ), regardless of an FT4 drop. For delayed TSH elevation, proportions within the previous preterm or low birth weight study cohorts ranged from 50.9 to $100 \%$ (this study, $82.4 \%$ ). Hypothyroidism with delayed TSH elevation in most cases was transient, but up to $31.3 \%$ of infants with delayed TSH elevation had permanent hypothyroidism (this study, 16.6\%). The lowest proportion of permanent hypothyroidism with late TSH rise $(2 / 16 ; 12.5 \%)$ was reported in the only study that included FT4 values as a criterion for final diagnosis [32]. Previously reported proportions ranged from 20.5 to 50\% for permanent hypothyroidism (this study, 
$27.5 \%$ ), and from 20.8 to $84.4 \%$ for transient hypothyroidism (this study, $45.1 \%$ ) among very preterm infants. Up to $15 \%$ of the cases were lost to follow-up (this study, $9.8 \%$ ), and in up to $28.3 \%$ of the cases the final diagnosis remained unclear (this study, $17.6 \%$ ). Taken together, consistent with the present study, previous research identified similar patterns of results, such as frequent delayed TSH elevation and frequent transient hypothyroidism, but also permanent hypothyroidism with delayed TSH elevation, among preterm or low birth weight infants.

In the present study cohort, all cases of severe permanent hypothyroidism without a known confounding factor had a high TSH value at first screening. The lowest gestational age with a positive first TSH screening was 27 weeks in this cohort, in the literature [28] and in the German nationwide NBS data (unpublished, personal communication) even 23 weeks. Thus, an immaturity of the HPT axis, widely cited as a major argument for the importance of repeat samples, did not necessarily compromise TSH screening before 32 weeks of gestation.

The observed threefold elevated prevalence of permanent hypothyroidism in the very preterm study group was unexpected [10,29] and may be connected with the high number of twins among the permanent cases, as multiple gestation pregnancies frequently lead to preterm birth and are known risk factors for congenital hypothyroidism [1,35]. In addition, because of the implementation of repeat NBS only among preterms, the detection rate of moderate dyshormonogenesis might have been expedited, e.g., the detection of DUOX2 mutations, which seem to have a potential of being undetected in initial NBS, regardless of gestational age [1,36-38].

In accordance with the literature, the prevalence of transient hypothyroidism was highly increased among very preterm infants born at less than 32 weeks of gestation. For the most part, one obvious reason for the observed transient hypothyroidism, like iodine exposure, could not be identified. The contribution of some immaturity or vulnerability of the HPT axis cannot be excluded, nor can iodine deficiency in an iodine-poor region with partial insufficient iodine uptake in spite of prophylactic programmes [39]. Mainly, transient hypothyroidism was likely attributed to thyroid function imbalances occurring in the context of severe neonatal morbidities and NICU treatment, the phenomenon referred to as the non-thyroidal illness (NTI) syndrome or euthyroid sick syndrome [6-8,40]. The observed significant male preponderance among transient hypothyroidism, as similarly reported in other publications [1], may confirm the role of NTI, reflecting the higher complication and morbidity rates among male preterm infants [41].

Despite expected tendencies of differences between the diagnostic groups, neither the extent of screening or serum TSH elevations nor FT4 values allowed a definite prognostic differentiation between permanent and transient forms, as noted in other publications [11,42]. LT4 dosage results for the age of 2 years in the study [1] cohort correlated well with the discriminative thresholds around $2-2.5 \mu \mathrm{g} / \mathrm{kg}$ that are found in the literature to assess the likelihood of permanence or transiency for ages 2-3 years [43-45].

The number of children with the final status "inconclusive", treated with the same LT4 dose over years without the involvement of a paediatric endocrinologist, was relatively high. These cases may confirm the previously described "problem ... that thyroid hormone replacement therapy is easy to start and hard to terminate" [25]. Parental concerns, paediatricians' doubts, or ignorance regarding guideline recommendations [46] or the challenges of interpreting laboratory results after a trial off-treatment [47] may be reasons for omitted termination of therapy. A comprehensive re-evaluation of the thyroid axis in these inconclusive cases very likely would have led to a diagnosis of transient hypothyroidism, mild dyshormonogenesis [48], or receptor gene mutations [49].

While a few authors believe that repetitive TSH screening for preterm infants is unnecessary or even harmful $[10,29,50]$, most authors and guidelines advocate repeating hypothyroidism screening in preterm and LBW infants [1,18]. The main arguments for re-screening very preterm infants, namely a general immaturity of the HPT axis or a preterm-specific problem of delayed TSH rise, are not supported by the present results 
but cannot be safely refuted either. From the perspective of the current guidelines [1], the results seem to confirm the necessity of at least one repeat TSH screening for very preterm infants. However, the main outcome of routine repeat screening was the detection of transient and mild cases, for which the benefit of therapy has not been proven on the basis of evidence $[1,10,51]$, and a substantial number of children were inadequately treated longer than recommended. Thus, recommendations of repeat screenings should be complemented by measures to minimise overtreatment such as ensuring competent re-evaluation of the individual need to treat as early as possible. In addition, preterm and intensively treated children would benefit from more differentiated criteria for initiating FT4 therapy that take into account not only TSH but also FT4 and changes in thyroid function tests over time. For this, research on normative thyroid function values, adjusted both for age and gestational age would be crucial, as several authors have already stated $[12,47,52,53]$. Finally, the much-mentioned lack of treatment outcome studies $[1,10,30,37,47]$, perhaps caused by ethical and methodological difficulties $[10,13,51,54]$, appears to be a major limitation in developing screening recommendations.

This study has several limitations. The definition of the methodology was complicated by discrepancies in terminology and content among experts and in the literature. Despite the long study period and the population-based data set, the total number of cases was relatively low. The quality of medical reports and follow-up data was heterogeneous. Due to possible repeat screening gaps during the first third of the study period, the exclusion of infants with syndromes or malformations, and the number of unknown and inconclusive final diagnoses, the frequency of both transient and permanent hypothyroidism or TSH elevation among the very preterm infants may have been underestimated.

Despite its limitations, the present population-based study with a high follow-up rate confirmed previous findings and contributes to the existing knowledge on preterm hypothyroid disorders. This study included the largest number of hypothyroid infants born below 32 weeks of gestation so far and appears to be the first report on population-based stratified prevalence. Some findings of this study suggest possible courses of action on the translation of guideline recommendations into practice, such as repeat hypothyroidism screening for same-sex twins, timely initiation of thyroid re-evaluation, or inclusion of paediatric endocrine experts. Furthermore, the study clearly highlights the importance of further research on specific thyroid function normative values and controlled treatment outcome studies to enable evidence-based recommendations on hypothyroidism screening for the particularly vulnerable group of very preterm infants.

\section{Conclusions}

Most experts consider a TSH repeat screening strategy important in very preterm infants, based on reports of delayed TSH rise. In this study cohort, the majority of cases were indeed detected only through repeat screening. Still, the results could not unequivocally confirm a serious problem of delayed TSH rise in congenital hypothyroidism which would be directly associated with prematurity. Repetitive TSH screening mainly detected transient and mild cases, for which the benefit of therapy has not been proven [1,10,51], and frequently the duration of treatment was considerably longer than recommended by guidelines. Thus, it can be questioned to what extent repetitive screening strategies are compatible with the accepted screening principles $[10,55]$ which call for a recognised therapeutic benefit [56] and state that "the overall benefits of screening should outweigh the potential harms" [57]. Evidence-based recommendations concerning the ideal hypothyroidism NBS algorithm for very preterm infants require further research. The European guideline recommendation of a one-time repeat screening at the age of two weeks most appropriately reflects the current state of research. When recommending subsequent NBS repetitions, the risks of short- and long-term overtreatment must be taken into account. At any rate, in order to avoid over-therapy and to ensure the earliest possible re-evaluation of thyroid function, for all very premature infants with hypothyroidism detected via repeat NBS, the involvement of a paediatric endocrinologist is of particular importance. 
Author Contributions: Conceptualization, B.O., B.L., H.S., U.N.; methodology, B.O., A.F., W.R., H.S., U.N.; literature research, B.O., A.F., W.R.; validation, B.O., A.F., H.S., U.N.; formal analysis, B.O., A.F., U.N.; investigation, B.O., A.F.; data curation, B.O., A.F.; writing-original draft preparation, B.O., A.F.; writing-review and editing, B.O., A.F., W.R., B.L., H.S., U.N.; visualization, B.O., A.F.; supervision, B.L., H.S., U.N.; project administration, B.O., U.N.; B.O. and A.F. contributed equally to this work, as did H.S. and U.N. All authors have read and agreed to the published version of the manuscript.

Funding: This research received no external funding.

Institutional Review Board Statement: The study was conducted according to the guidelines of the Declaration of Helsinki, and approved by the Ethics Commission of the Bavarian State Chamber of Physicians (Ethikkommission der Bayerischen Landesärztekammer, project identification code 04016, approval date 23 March 2004).

Informed Consent Statement: Informed consent was obtained from the parents of all subjects involved in the study.

Data Availability Statement: The data presented in this study are available on request from the corresponding author. The data are not publicly available due to privacy restrictions.

Acknowledgments: We would like to thank the Bavarian screening and follow-up teams for their support and the laboratories, and paediatricians, and families for providing data and answering many questions. The article includes data from the dissertation by A.F. for a medical degree at the Ludwig-Maximilian-University of Munich. Particular thanks are due to Heiko Krude, Berlin, for intense discussion of the data.

Conflicts of Interest: The authors declare no conflict of interest.

\section{References}

1. van Trotsenburg, A.S.; Stoupa, A.; Léger, J.; Rohrer, T.R.; Peters, C.; Fugazzola, L.; Cassio, A.; Heinrichs, C.; Beauloye, V.; Pohlenz, J.; et al. Congenital hypothyroidism: A 2020 consensus guidelines update An ENDO-EUROPEAN REFERENCE NETWORK (ERN) initiative endorsed by the European Society for Pediatric Endocrinology and the European Society for Endocrinology. Thyroid 2021, 31, 387-419. [CrossRef]

2. Krude, H.; Kühnen, P.; Biebermann, H. Treatment of congenital thyroid dysfunction: Achievements and challenges. Best Pract. Res. Clin. Endocrinol. Metab. 2015, 29, 399-413. [CrossRef]

3. Léger, J.; Olivieri, A.; Donaldson, M.; Torresani, T.; Krude, H.; van Vliet, G.; Polak, M.; Butler, G. European Society for Paediatric Endocrinology consensus guidelines on screening, diagnosis, and management of congenital hypothyroidism. Horm. Res. Paediatr. 2014, 81, 80-103. [CrossRef]

4. Chung, H.R. Screening and management of thyroid dysfunction in preterm infants. Ann. Pediatr. Endocrinol. Metab. 2019, 24, 15-21. [CrossRef] [PubMed]

5. Fisher, D.A. Thyroid system immaturities in very low birth weight premature infants. Semin. Perinatol. 2008, 32, 387-397. [CrossRef] [PubMed]

6. Williams, F.L.R.; Ogston, S.A.; van Toor, H.; Visser, T.J.; Hume, R. Serum thyroid hormones in preterm infants: Associations with postnatal illnesses and drug usage. J. Clin. Endocrinol. Metab. 2005, 90, 5954-5963. [CrossRef]

7. Golombek, S.G. Nonthyroidal illness syndrome and euthyroid sick syndrome in intensive care patients. Semin. Perinatol. 2008, 32, 413-418. [CrossRef]

8. Zung, A.; Bier Palmon, R.; Golan, A.; Troitzky, M.; Eventov-Friedman, S.; Marom, R.; Keidar, R.; Kats, N.; Almashanu, S.; Flidel-Rimon, O. Risk Factors for the Development of Delayed TSH Elevation in Neonatal Intensive Care Unit Newborns. J. Clin. Endocrinol. Metab. 2017, 102, 3050-3055. [CrossRef]

9. Chaudhari, M.; Slaughter, J.L. Thyroid Function in the Neonatal Intensive Care Unit. Clin. Perinatol. 2018, 45, 19-30. [CrossRef] [PubMed]

10. Grob, F.; van Vliet, G. Avoiding the Overdiagnosis of Congenital Hypothyroidism in Premature Newborns. Pediatrics 2019, 144, e20191706. [CrossRef] [PubMed]

11. Zung, A.; Radi, A.; Almashanu, S. The natural history of congenital hypothyroidism with delayed TSH elevation in neonatal intensive care newborns. Clin. Endocrinol. 2020, 92, 443-449. [CrossRef]

12. Hijman, A.-I.; Konrad, D.; Fingerhut, R. Determining Reference Ranges for Total T4 in Dried Blood Samples for Newborn Screening. Int. J. Neonatal Screen. 2020, 6, 17. [CrossRef] [PubMed]

13. Williams, F.L.R.; Lindgren, A.; Watson, J.; Boelen, A.; Cheetham, T. Thyroid function in preterm infants and neurodevelopment at 2 years. Arch. Dis. Child. Fetal Neonatal Ed. 2020, 105, 504-509. [CrossRef] [PubMed]

14. Osborn, D.A.; Hunt, R.W. Prophylactic postnatal thyroid hormones for prevention of morbidity and mortality in preterm infants. Cochrane Database Syst. Rev. 2007, 1, CD005948. [CrossRef] [PubMed] 
15. Alvarez, M.; Iglesias Fernández, C.; Rodríguez Sánchez, A.; Dulín Lñiguez, E.; Rodríguez Arnao, M.D. Episodes of overtreatment during the first six months in children with congenital hypothyroidism and their relationships with sustained attention and inhibitory control at school age. Horm. Res. Paediatr. 2010, 74, 114-120. [CrossRef] [PubMed]

16. Bongers-Schokking, J.J.; Resing, W.C.M.; de Rijke, Y.B.; de Ridder, M.A.J.; de Muinck Keizer-Schrama, S.M.P.F. Cognitive development in congenital hypothyroidism: Is overtreatment a greater threat than undertreatment? J. Clin. Endocrinol. Metab. 2013, 98, 4499-4506. [CrossRef]

17. Eugster, E.A.; LeMay, D.; Zerin, J.M.; Pescovitz, O.H. Definitive diagnosis in children with congenital hypothyroidism. J. Pediatr. 2004, 144, 643-647. [CrossRef]

18. LaFranchi, S.H. Screening preterm infants for congenital hypothyroidism: Better the second time around. J. Pediatr. 2014, 164, 1259-1261. [CrossRef]

19. Hashemipour, M.; Hovsepian, S.; Ansari, A.; Keikha, M.; Khalighinejad, P.; Niknam, N. Screening of congenital hypothyroidism in preterm, low birth weight and very low birth weight neonates: A systematic review. Pediatr. Neonatol. 2018, 59, 3-14. [CrossRef]

20. Richtlinie des Gemeinsamen Bundesausschusses über die Früherkennung von Krankheiten bei Kindern (Kinder-Richtlinie): Kinder-Richtlinie. 2020. Available online: https:/ / www.g-ba.de/downloads/62-492-2432/Kinder-RL_2020-12-17_iK-2021-0401.pdf (accessed on 28 April 2021).

21. Nennstiel-Ratzel, U.; Lüders, A.; Fusch, C.; Mohnike, K. Neugeborenen-Screening bei Frühgeborenen: Noch Raum für Verbesserungen. Z. Geburtshilfe Neonatol 2013, 217, V22_4. [CrossRef]

22. DGNS e.V.-Deutsche Gesellschaft für Neugeborenenscreening. Nationaler Screeningreport. Available online: https://www. screening-dgns.de/reports.php (accessed on 25 February 2021).

23. Bijarnia, S.; Wilcken, B.; Wiley, V.C. Newborn screening for congenital hypothyroidism in very-low-birth-weight babies: The need for a second test. J. Inherit. Metab. Dis. 2011, 34, 827-833. [CrossRef] [PubMed]

24. Woo, H.C.; Lizarda, A.; Tucker, R.; Mitchell, M.L.; Vohr, B.; Oh, W.; Phornphutkul, C. Congenital hypothyroidism with a delayed thyroid-stimulating hormone elevation in very premature infants: Incidence and growth and developmental outcomes. J. Pediatr. 2011, 158, 538-542. [CrossRef] [PubMed]

25. Lim, G.; Lee, Y.K.; Han, H.-S. Early discontinuation of thyroxine therapy is possible in most very low-birthweight infants with hypothyroidism detected by screening. Acta Paediatr. 2014, 103, 123-129. [CrossRef] [PubMed]

26. Vigone, M.C.; Caiulo, S.; Di Frenna, M.; Ghirardello, S.; Corbetta, C.; Mosca, F.; Weber, G. Evolution of thyroid function in preterm infants detected by screening for congenital hypothyroidism. J. Pediatr. 2014, 164, 1296-1302. [CrossRef] [PubMed]

27. Jung, J.M.; Jin, H.Y.; Chung, M.L. Feasibility of an Early Discontinuation of Thyroid Hormone Treatment in Very-Low-BirthWeight Infants at Risk for Transient or Permanent Congenital Hypothyroidism. Horm. Res. Paediatr. 2016, 85, 131-139. [CrossRef] [PubMed]

28. Jaruratanasirikul, S.; Janjindamai, W.; Sriplung, H. Congenital hypothyroidism in preterm infants: A 3- to 8-year longitudinal study in southern Thailand. J. Pediatr. Endocrinol. Metab. 2019, 32, 1275-1282. [CrossRef] [PubMed]

29. Srinivasan, R.; Harigopal, S.; Turner, S.; Cheetham, T. Permanent and transient congenital hypothyroidism in preterm infants. Acta Paediatr. 2012, 101, 179-182. [CrossRef] [PubMed]

30. Lain, S.; Trumpff, C.; Grosse, S.D.; Olivieri, A.; van Vliet, G. Are lower TSH cutoffs in neonatal screening for congenital hypothyroidism warranted? Eur. J. Endocrinol. 2017, 177, 1-12. [CrossRef] [PubMed]

31. Fischer, A. Reevaluation des TSH-Neugeborenen-Screenings für Frühgeborene Kinder unter 32 Vollendeten Schwangerschaftswochen in Bayern im Zeitraum 1999 bis 2013. Ph.D. Thesis, Ludwig-Maximilians-Universität München, München, Germany, 2020.

32. Tylek-Lemanska, D.; Kumorowicz-Kopiec, M.; Starzyk, J. Screening for congenital hypothyroidism: The value of retesting after four weeks in neonates with low and very low birth weight. J. Med. Screen. 2006, 12, 166-169. [CrossRef]

33. McGrath, N.; Hawkes, C.P.; Mayne, P.; Murphy, N.P. Optimal Timing of Repeat Newborn Screening for Congenital Hypothyroidism in Preterm Infants to Detect Delayed Thyroid-Stimulating Hormone Elevation. J. Pediatr. 2019, 205, 77-82. [CrossRef]

34. Scavone, M.; Giancotti, L.; Anastasio, E.; Pensabene, L.; Sestito, S.; Concolino, D. Evolution of congenital hypothyroidism in a cohort of preterm born children. Pediatr. Neonatol. 2020, 61, 629-636. [CrossRef]

35. Olivieri, A.; Medda, E.; de Angelis, S.; Valensise, H.; de Felice, M.; Fazzini, C.; Cascino, I.; Cordeddu, V.; Sorcini, M.; Stazi, M.A. High risk of congenital hypothyroidism in multiple pregnancies. J. Clin. Endocrinol. Metab. 2007, 92, 3141-3147. [CrossRef]

36. De Zegher, F.; Vanderschueren-Lodeweyckx, M.; Heinrichs, C.; van Vliet, G.; Malvaux, P. Thyroid dyshormonogenesis: Severe hypothyroidism after normal neonatal thyroid stimulating hormone screening. Acta Paediatr. 1992, 81, 274-276. [CrossRef]

37. Heather, N.L.; Hofman, P.L.; de Hora, M.; Carll, J.; Derraik, J.G.B.; Webster, D. Evaluation of the revised New Zealand national newborn screening protocol for congenital hypothyroidism. Clin. Endocrinol. 2017, 86, 431-437. [CrossRef] [PubMed]

38. Peters, C.; Nicholas, A.K.; Schoenmakers, E.; Lyons, G.; Langham, S.; Serra, E.G.; Sebire, N.J.; Muzza, M.; Fugazzola, L.; Schoenmakers, N. DUOX2/DUOXA2 Mutations Frequently Cause Congenital Hypothyroidism that Evades Detection on Newborn Screening in the United Kingdom. Thyroid 2019, 29, 790-801. [CrossRef]

39. Bundesinstitut für Risikobewertung. Iodine Intake in Germany on the Decline Again: Tips for a Good Iodine Supply. Questions and Answers on Iodine Supply and the Prevention of Iodine Deficiency. Available online: https://www.bfr.bund.de/en/iodine_ intake_in_germany_on_the_decline_again_tips_for_a_good_iodine_supply-128779.html (accessed on 5 January 2021). 
40. Yoon, S.A.; Chang, Y.S.; Ahn, S.Y.; Sung, S.I.; Park, W.S. Incidence and severity of transient hypothyroxinaemia of prematurity associated with survival without composite morbidities in extremely low birth weight infants. Sci. Rep. 2019, 9, 9628. [CrossRef] [PubMed]

41. O'Driscoll, D.N.; McGovern, M.; Greene, C.M.; Molloy, E.J. Gender disparities in preterm neonatal outcomes. Acta Paediatr. 2018, 107, 1494-1499. [CrossRef]

42. Park, E.S.; Yoon, J.Y. Factors associated with permanent hypothyroidism in infants with congenital hypothyroidism. BMC Pediatr. 2019, 19, 453. [CrossRef] [PubMed]

43. Park, I.S.; Yoon, J.S.; So, C.H.; Lee, H.S.; Hwang, J.S. Predictors of transient congenital hypothyroidism in children with eutopic thyroid gland. Ann. Pediatr. Endocrinol. Metab. 2017, 22, 115-118. [CrossRef]

44. Scavone, M.; Carboni, E.; Stefanelli, E.; Romano, G.; Vero, A.; Giancotti, L.; Miniero, R.; Talarico, V. Prediction of Transient or Permanent Congenital Hypothyroidism from Initial Thyroid Stimulating Hormone Levels. Indian Pediatr. 2018, 55, 1059-1061. [CrossRef]

45. Zdraveska, N.; Zdravkovska, M.; Anastasovska, V.; Sukarova-Angelovska, E.; Kocova, M. Diagnostic re-evaluation of congenital hypothyroidism in Macedonia: Predictors for transient or permanent hypothyroidism. Endocr. Connect. 2018, 7, $278-285$. [CrossRef] [PubMed]

46. Ford, G.A.; Denniston, S.; Sesser, D.; Skeels, M.R.; LaFranchi, S.H. Transient versus Permanent Congenital Hypothyroidism after the Age of 3 Years in Infants Detected on the First versus Second Newborn Screening Test in Oregon, USA. Horm. Res. Paediatr. 2016, 86, 169-177. [CrossRef] [PubMed]

47. Mitchell, M.L.; Hsu, H.-W. Unresolved Issues in the Wake of Newborn Screening for Congenital Hypothyroidism. J. Pediatr. 2016, 173, 228-231.e1. [CrossRef]

48. Kwak, M.J. Clinical genetics of defects in thyroid hormone synthesis. Ann. Pediatr. Endocrinol. Metab. 2018, 23, 169-175. [CrossRef] [PubMed]

49. Vigone, M.C.; Di Frenna, M.; Guizzardi, F.; Gelmini, G.; de Filippis, T.; Mora, S.; Caiulo, S.; Sonnino, M.; Bonomi, M.; Persani, L.; et al. Mild TSH resistance: Clinical and hormonal features in childhood and adulthood. Clin. Endocrinol. 2017, 87, 587-596. [CrossRef]

50. Korada, M.; Pearce, M.S.; Ward Platt, M.P.; Avis, E.; Turner, S.; Wastell, H.; Cheetham, T. Repeat testing for congenital hypothyroidism in preterm infants is unnecessary with an appropriate thyroid stimulating hormone threshold. Arch. Dis. Child. Fetal Neonatal Ed. 2008, 93, 286-288. [CrossRef]

51. van Vliet, G.; Diaz Escagedo, P. Redefining Congenital Hypothyroidism? J. Clin. Endocrinol. Metab. 2021, 106, 1463-1465. [CrossRef]

52. Wassner, A.J. Pediatric Hypothyroidism: Diagnosis and Treatment. Paediatr. Drugs 2017, 19, 291-301. [CrossRef]

53. Kaluarachchi, D.C.; Allen, D.B.; Eickhoff, J.C.; Dawe, S.J.; Baker, M.W. Thyroid-Stimulating Hormone Reference Ranges for Preterm Infants. Pediatrics 2019, 144, e20190290. [CrossRef]

54. Pollitt, R.J. Evidence or enthusiasm? Why yields from UK newborn screening programmes for congenital hypothyroidism are increasing. Arch. Dis. Child. 2016, 101, 120-123. [CrossRef]

55. Krude, H.; Blankenstein, O. Treating patients not numbers: The benefit and burden of lowering TSH newborn screening cut-offs. Arch. Dis. Child. 2011, 96, 121-122. [CrossRef] [PubMed]

56. Watson, M.S. Current status of newborn screening: Decision-making about the conditions to include in screening programs. Ment. Retard. Dev. Disabil. Res. Rev. 2006, 12, 230-235. [CrossRef] [PubMed]

57. Andermann, A.; Blancquaert, I.; Beauchamp, S.; Déry, V. Revisiting Wilson and Jungner in the genomic age: A review of screening criteria over the past 40 years. Bull. World Health Organ. 2008, 86, 317-319. [CrossRef] [PubMed] 